\title{
Um estudo das edições de Ou isto ou aquilo, de Cecília Meireles'
}

N orma Sandra de Almeida Ferreira*

Resumo: Localizar em sua materialidadea obra 0 u isto ou aquilo, deC ećlilia M eireles, em suas edições - 1964; 1969; 1977; 1987; 1990; 2002 - ; cotejá-las para compreender as formas pelas quais os textos são apresentados aos seusleitores, em diferentestempos; eindagar como e por que essas formas são pensadas e con cretizadas são desafios deste artigo. Esta pesquisa de cunho exploratório, à luz, principalmente, dos estudos da $\mathrm{H}$ istória Cultural, privilegia, no exame das diferentes edições, as partes externas queenvolvem os poemas (o texto propriamente dito) esuasilustrações. I dentifica ediscutea produção de sentidos eval ores ligados à educação do leitor, ao reconhecimento deuma escritora con sagrada pela tradição literária, à singularidade da linguagem, à importância de uma prática prazerosa da leitura.

Palavras-chave: literaturainfantil; leitura; história das edições; leitor.

\section{A study of Cecilia Meirelles' Ou isto ou aquilo editions}

Abstract: This articlebrings the challenges of locating $\mathrm{C}$ ecília M eireles' book $\mathrm{O} u$ isto ou aquilo (Either this or that) in its material ness, with considerations on its 1964, 1969, 1977, 1987, 1990 and 2002 editions, as well as comparing theseeditionsin order to understand theforms in which texts are presented to their readers at different times, and questioning how and why theseforms are conceived and put into practice. In thelight of studies on cultural history, in theanalysis of the different editions, this exploratory research prioritizes the external partsthat involve poems (the texts themselves) and their illustrations. It providesidentification and a discussion on theproduction of senses and valuesrelated to readers' education, the recognition of a writer who is consecrated by literary tradition, the uniqueness of thelanguage used, and theimportance of pleasant reading practice.

Key words: children'sliterature; reading; history of theeditions; reader.

\footnotetext{
* Professora do Departamento de Educação, Conhecimento, Linguagem e Arte (Delart) e membro do Grupo de Pesquisa Alfabetização, Leitura e Escrita (ALLE) da Faculdade de Educação da Unicamp, Campinas, SP, Brasil.normasandra@yahoo.com.br

I. Este texto, com algumas alterações, foi apresentado na Jornada de Lectura e Escritura Del Litoral, Faculdad de Humanidades y Ciências de La Universidad Nacional Del Litoral, Santa Fé/ Argentina, no período de $21 / 09$ a 23/09/2006.
} 


\section{A história dos livros}

O s livros impressos, segundo Darnton (1990), surgem e difundem-se pela sociedade, passando por um ciclo de vida que se inicia com o autor e se prolonga pelo editor (livreiro, às vezes), pelo impressor, pelo distribuidor, pelo vendedor, até finalizar com o leitor.

A cada nova edição, um "novo livro" percorre novamente o mesmo circuito, porém sujeito a novas tensões, movimentos, direções, instaurados por alterações em qualquer dos segmentos que compõem a cadeia entre autor e leitor. São diferentes livros - já que projetos editoriais distintos - de uma obra originalmente pensada pelo autor, mas continuamente transformada no percurso de novas edições, mediada por outras editoras, exposta pelos vendedores para outros leitores e autorizada para publicação pelo autor ou por seus herdeiros.

Para uma empreitada em torno da história dos livros impressos, em condições exeqüíveis, pode-se fazer um estudo sobre qualquer um desses segmentos do circuito, como, por exemplo, o papel dos editores na publicação de certa obra. O u, então, interessar-se pelo ciclo de vida de um determinado texto, em todas as suas etapas. $\mathrm{O} u$, ainda, reconhecer como determinado livro que esteve (ou está) em circulação, com grande sucesso entre seus leitores, traz inscritas, em suas diferentes edições, marcas dos agentes envolvidos em seu processo de composição.

0 presente trabalho insere-se nesta perspectiva e toma como desafio aproximar a obra $\mathrm{O}$ u isto ou aquilo, de Cecília M eireles, em suas seis edições (1964; 1969; 1977; 1987; 1990; 2002); cotejá-las para compreender as formas pelas quais os textos são apresentados aos seus leitores, em diferentes tempos; e indagar como e por que essas formas são pensadas e concretizadas.

O s estudos da H istória Cultural (Chartier, 1996a; 1996b; Chartier; Cavallo, 1998) vêm destacando, entre outras idéias, a de que não existe texto fora das circunstâncias e do suporte em que é dado a ler ou a ouvir. As reflexões de Chartier propõem a leitura como prática, entendida, por um lado, em sua relação com o leitor e suas habilidades, competências, necessidades, desejos; e, por outro, com um texto carregado das intenções do autor/editor/ilustrador, pressupondo determinadas finalidades de uso, configurado em um gênero do discurso e materializado em um suporte.

$\mathrm{N}$ essa perspectiva, $\mathrm{O}$ u isto ou aquilo, publicada em condições de produção distintas, permite interrogar por que uma obra é "reinventada" e assume projetos editoriais tão diferentes entre si, a cada edição.

Segundo Chartier (1996), dois modelos de compreensão explicam os textos, os livros e as suas leituras. 
0 primeiro põe em contrastedisciplina einvenção, considerando essas categorias não como antagônicas, mas como sendo geridas a par. Todo o dispositivo que visa criar o controle e condicionamento segrega sempretáticas queo domesticam ou o subvertem; contrariamente, não há produção cultural que não empreguemateriaisimpostos pela tradição, pela autoridadeou pelo mercado equenão esteja submetida às vigilânciase às censuras dequem tem poder sobre as palavras e ou os gestos (op. cit., p.137) [...] D isciplina einvenção mastambém distinção edi vulgação. Estesegundo par permite propor uma compreensão da circulação dos objetos ou dos model os culturais quenão se reduz a simples difusão, pensada geralmente como um movimento descendentena escala social. 0 s processos de imitação ou vulgarização são maiscomplexosemaisdinâmicos e devem ser entendidos, antes de mais nada, como lutas de concorrência ondetoda a divulgação, concedida ou conquistada, produz imediatamente a procura deuma nova distinção. (op. cit., p.138, grifosnossos).

U m olhar exploratório para as edições de $\mathrm{Ou}$ isto ou aquilo permite reconhecer esse movimento no tempo, marcado por tradição e invenção, assumindo aspectos que permitem a identificação da obra como tal e a criação de outros, responsáveis por dar ao conhecido uma nova roupagem, o que torna a obra distinta e possibilita sua permanência e sua divulgação no mercado editorial.

Uma vez mudados os leitores efetivos - no decorrer do tempo ou no interior de uma mesma sociedade - , com seus códigos de interpretação; suas expectativas e seus interesses; seus usos e modos de ler, pressupõem-se outras práticas de leitura que determinam mudanças nos modos de apresentação do texto. O s textos escritos pelos seus autores, mesmo que inalterados, mantendo a estabilidade no conteúdo e na linguagem, recebem intervenções de ordem tipográfica orientadas pela representação que se tem do leitor pressuposto para eles (C hartier, 1996).

N esse esforço, protocolos de leitura (op.cit.) são acionados e incluídos em prefácios, orelhas, índices, capas, para que leitores e escritores compartilhem de um repertório comum de referências e formas de apropriação que permitam o (re)encontro com a obra. Dispositivos tipográficos - inclusão de imagens, destaque pela cor ou pelo tamanho das letras, entre outros,

dão suportes móveis às possíveis atualizações do texto, permitindo um comércio perpétuo entretextos imóveiseleitores que mudam, traduzindo no impresso as mutações dehorizontes de expectativas do público e propondo novos significados além daquelas que 0 autor pretendia ao impor aos seus primeiros leitores. (Chartier, 1996, p. 98). 
Ao tomarmos nas mãos as seis edições, privilegiando, no seu exame, as partes externas que envolvem os poemas - o texto, propriamente dito - e suas ilustrações, "alterações tipográficas - na distinção entre texto e impresso, entre o trabalho de escrita e fabricação do livro" (Chartier, 1996, p.126), facilmente se constata que cada edição guarda certa autonomia e, ao mesmo tempo, certa dependência em relação às demais.

Sob pena de desaparecer, esquecida ou incompreendida pelos novos leitores, $\mathrm{Ou}$ isto ou aquilo passa a trazer traços e a carregar, a sua volta, textos que possam torná-la familiar, garantir sua contemporaneidade e inscrevêla na memória de seus leitores.

\section{A autora e a obra}

São muitas as obras para adultos e crianças escritas por Cecília M eireles. Publicadas para diferentes gerações de leitores, premiadas nacional e internacionalmente, presentes nos acervos selecionados para escolas públicas, elas ganham várias edições e projetos gráficos diferentes.

A produção crítica em torno dessa autora já é bastante conhecida e difundida no nosso país. Sobre suas obras infantis é destacada a forma de lidar com a linguagem; a concretude da sonoridade e do movimento da palavra; a exploração do lirismo, em prosa ou em verso, que escancara, que desnuda, que dialoga com as perplexidades, com os impasses, com as utopias do ser humano. Às suas obras é creditado 0 abandono do tom persuasivo dos versos escritos pelo adulto para educar a criança de forma autoritária. A elas é atribuído o uso do tom de cumplicidade na anticonvencionalidade, quer da linguagem, quer do modo de ver 0 mundo; na fragilidade entre sonho e realidade, entre certezas e hesitações, entre instabilidades e rigidez, entre seriedade e humor. A propósito das ilustrações que acompanham seus poemas nas edições de $0 \mathrm{u}$ isto ou aquilo, ver o estudo de Camargo (1998); e sobre a especificidade da linguagem literária destinada ao leitor infantil, a produção de Lajolo e Zilberman (1988; 1993), de Zilberman (1982) e de Perrotti (1986; 1990), entre outros.

$\mathrm{N}$ a história do gênero literatura infantil, $\mathrm{O}$ u isto ou aquilo é considerada uma obra que rompe com uma tradição ligada exclusiva e predominantemente à produção de poemas recheados de conselhos, normas, ensinamentos, orientados por uma pedagogia com valores tradicionais, predominantes até a década de 1960.

Junto com outros escritores, Cecília M eireles faz parte de um movimento para o fortalecimento do gênero literatura infantil, como produção nacional e como obra que as "crianças lêem com agrado" (M eireles, 1951, p. 97), no lugar daquela que se escreve para elas. Para essa autora, "Um livro de Literatura 
Infantil é, antes de mais nada, uma obra literária. N em se deveria consentir que as crianças freqüentassem obras insignificantes para não perderem tempo e prejudicarem seu gosto." (op.cit., p. 123).

Ao longo desses 40 anos, em todas as suas edições (1964; 1969; 1977; 1987; 1990; 2002) a obra 0 u isto ou aquilo ganhou diferentes ilustradores, formatos e tamanhos, cores e traços e é marcadamente reconhecida pela crítica literária como um livro de literatura infantil, ou infanto-juvenil, de poesia brasileira.

\section{A primeira e a segunda edições - um leitor sem idade}

Q uanto mais voltamos no tempo, mais evidente fica a proposta editorial de proporcionar 0 encontro singular entre o leitor (não necessariamente infantil) e o livro destinado a ele. Encontro entre o livro, como uma "caixinha de surpresas", e o leitor, que se surpreende, em sobressalto. Q uase a concretização das idéias de M eireles:

[...] à criança competiria escolher o livro querealmentelheagradasse (referimo-nos ao livro recreativo, e não ao compêndio escolar ou livro de texto). Acontece, porém, que é o adulto quem geralmenteescreve, edita, julga ecritica oslivros destinadosà criança- eem todosesses exercícios muito freqüentemente seesquece desua condição.[...] 0 squeadmitiram a possibilidade de ser a literatura infantil julgada pelas próprias crianças imaginaram a existência de bibliotecas especializadas, ondeos leitores, com liberdade de escolha, edeopinião, prestariam o serviço deinformar indiretamente sobreas obras maisadequadas às diferentes idades, ea cada sexo, - de onde decorreriam as outrasinformações relativasa gêneros, autores, etc. (M eireles, 1942, p. 339-341).

A edição de 1964 parece dar ao leitor a possibilidade de julgar a literatura infantil com liberdade de escolha e de opinião sobre o livro que realmente lhe agrade. Em uma crônica publicada no Corréo da $M$ anhã, no ano do lançamento, Carlos D rummond de Andrade (1964) contesta o público a que a obra se destina: "crianças, apenas? Tenho para mim que adultos se encantaram com este livro novo que não é para eles" (p. 6, 10 Caderno); e mais adiante completa: "encontro do pequeno com a poesia: sorte dos garotos que toparem com essa caixa de surpresas. [...] N ão sei se passo o livrinho ao pessoal miúdo da minha roda ou se fico com ele para mim.".

O u isto ou aquilo, única edição de 1964 - única com Cecília ainda em vida - , tem um formato totalmente diferente das demais edições: comprido, retangular, com dimensões de $31,5 \mathrm{~cm} \times 12 \mathrm{~cm}$, capa dura, em duas cores e 
poderia ser, hoje, confundida com um catálogo, com uma agenda telefônica. A capa abraça folhas coloridas, em papel cartão, que podem ser lidas na ordem desejada pelo leitor. "Uma caixa de surpresas, um livrinho comprido, com cara de brinquedo, ou de bicho, na coleção Giroflé - Giroflá, da editora Giroflé de SP", conforme esclarece D rummond na referida crônica.

Embaixo do título $\mathrm{O} u$ isto ou aquilo, a chamada para a autoria também é inusitada: "Cecília M eireles escreveu e M aria Bonomi ilustrou". N as capas da frente (em vermelho e amarelo) e de trás (em marrom e amarelo), os traços ondulados sugerem o movimento de um rio, em direção ao alto da capa. Um tronco de árvore, também ondulado, porém horizontalmente, atravessa e ocupa as duas capas. Como que espelhados em cada uma delas: um barco, um barqueiro com seus remos e um fruto preso no tronco. $\mathrm{Na}$ alternância sóbria do amarelo com o vermelho ou com o marrom, o desdobramento do mesmo desenho - na capa da frente e na de trás - estabelece um jogo sutil "ou isto ou aquilo", e não se pode estabelecer onde ele começa ou acaba. $\mathrm{N}$ a capa de trás, a informação "Editora G iroflê S.A. M arquês de Itu, 266, s. 33, São PauIo", escrita verticalmente, como subindo pela capa, acompanha a direção do "rio". No alto dela, quase saindo de dentro do livro, o símbolo da editora, um cata-vento. $N$ ão há referência alguma que permita ao leitor contemporâneo identificar a obra como destinada à criança, a não ser os verbos "escreveu", "ilustrou", que indicam autoria, na capa.

E se, por um momento, folheamos o livro, notamos que a ilustração da capa é a mesma que acompanha o poema "Rômulo rema", que no interior da obra aparece em azul e preto. $\mathrm{N}$ a leitura do poema, pistas para o entendimento do fruto desenhado - romã.

0 índice, no final do livro, também provoca um estranhamento no leitor de hoje. O s títulos dos vinte poemas estão jogados pelas duas páginas e há, para cada um deles, no lugar da indicação da página, um desenho em preto, não facilmente identificável à primeira vista. Com o manuseio da obra, é possível dizer que cada desenho do índice é um pedacinho da ilustração que acompanha o poema. Por exemplo, em "M oda da menina trombuda" o índice apresenta um desenho que parece uma borboleta; mas, buscando a ilustração no texto, percebemos tratar-se do laço que segura as tranças da menina. Índice no índice. Um jogo.

U m jogo para ser brincado em uma combinação lúdica entre o que oferece um índice sem numeração e as folhas soltas, também sem numeração. A página de rosto e a que fecha o livro trazem, ambas, o cata-vento em pé, com o cabo centralizado entre as páginas. $\mathrm{N}$ a penúltima página, os nomes dos livros - e de seus autores e ilustradores - publicados pela Giroflé-Giroflá, coleção cuja proposta era inovar a produção voltada para as crianças e que alcançou, na 
época, sucesso de crítica e fracasso de vendas.

Ao leitor é oferecido um projeto gráfico em que não reconhecemos a representação de uma criança com seus bichinhos, com flores, em cores em tom pastel, tal como costumeiramente presente nos livros infantis atuais. Antonio Olinto, em crônica de 10 de março de 1970 (apud Camargo, 1998, p. 78), afirma: "Este livro de Cecília M eireles é a exata execução do livro-objeto, já que poesia e formato físico do volume nele se juntam e se completam. M aria Bonomi foi responsável pelas ilustrações, belas, largas, soltas, no estilo mesmo dos poemas".

A segunda edição de 0 u isto ou aquilo, de 1969, publicação da M elhoramentos, diferentemente das demais, vem com o título Poesias $\mathrm{Ou}$ isto ou aquilo \& Inéditos. Ela incorpora 36 poemas, além dos 20 que compõem a primeira edição.

$\mathrm{N}$ as capas de fundo branco, uma árvore estilizada na cor verde tem um tronco que acompanha a lombada do livro e galhos que se esparramam, ocupando as capas. $\mathrm{N}$ a da frente, mais ao alto, metade de uma bola em tom vermelho amarronzado. $\mathrm{N}$ a de trás, embaixo, marcas no mesmo tom da bola lembram pegadas. As palavras do título estão jogadas uma embaixo da outra de forma alternada e o nome "C ecília M eireles", como que se abrindo: uma concha? U m gancho? U ma materialidade visual de jogo, de movimento, de dança das palavras?

Camargo (1998, p.79) identifica no projeto gráfico dessa edição "várias interferências nos títulos e na composição gráfica dos poemas, como deslocamento e inclinação de versos e estrofes, talvez inspirados em Apollinaire". É provável que a capa já anuncie essa intenção na concretude da forma, no desenho de um significado, na quebra da disposição gráfica convencional na folha em branco.

A ilustração singela no fundo claro das capas ganha beleza pela idéia de esparramamento e de movimento nos traços ondulados e com "fal has" de tinta na árvore, na bola, nas "pegadas". Segundo Camargo (1998, p.79), as ilustrações dessa edição

são predominantementemonotipias ou combinam monotipia eaquarela, uma linguagem artística, mais do queumatécnica dereprodução, em quea imagem resultante, inverso da imagem pintada, caracteriza-se por apresentar inúmeros pontos brancos, além de uma certairregularidade nas linhas eformas. (op. cit, 172).

Essa edição já permite ao leitor contemporâneo reconhecêla como uma obra de formato tradicional $(23 \mathrm{~cm} \times 15,5 \mathrm{~cm})$, com o nome da editora "M e- 
Ihoramentos" acompanhado de "MEC", embaixo, na capa da frente. A página de rosto informa, nessa seqüência, um abaixo do outro, os nomes da autora, do livro, da ilustradora, da coordenação artística e explicita o convênio: "Edições M elhoramentos em convênio com o Instituto Nacional do Livro - MEC".

Como vemos, cinco anos após o lançamento, $\mathrm{O}$ u isto ou aquilo inicia uma trajetória que será mantida em outras edições: autonomia em relação à Coleção na qual foi criada e participação no acervo escolar; logo, dirigida a um público leitor específico.

0 índice, diferentemente da primeira edição, tem a função que Ihe é própria: a de apresentar, grafados em preto, os títulos dos poemas na ordem em que aparecem no livro, com suas respectivas páginas, o que se manterá em todas as outras edições.

Tal como na anterior, nesta edição, sem folhear e sem perceber o jogo entre ilustração e escrita para cada poema, não se pode dizer, pelo "externo", que se trata de um livro de poemas para crianças, considerando que ele não traz uma ficha catalográfica nem, na ilustração, elementos tradicionalmente interpretados como pertencentes ao universo infantil. Em ambas as edições, o leitor infantil é provocado a encontrar sentidos pelo olhar e pelo manuseio da obra por ele mesmo e a avaliar se ela lhe serve ou não. N ão há, nas orelhas, nem na capa de trás ou em lugar algum, um texto (de um adulto) a mediar a leitura a ser realizada.

\section{A terceira e a quarta edições - um leitor infantil}

As edições de 1978 e 1987, de formato retangular, apresentam entre si pouca diferença em suas dimensões: $19,8 \mathrm{~cm} \times 27 \mathrm{~cm}$ e 21,5 cm x 28,5 cm, respectivamente. Ambas trazem marcas do leitor a que se destinam, como a inclusão da ficha catalográfica indicando "literatura infanto-juvenil" ou a criação de um jogo de sedução através das capas, que sugerem ao seu leitor, em cores, objetos e temas familiares do universo infantil. De qualquer maneira, distintamente das primeiras edições, começamos a perceber que a obra não se destina a um leitor "sem idade".

A edição de 1978 da Civilização Brasileira, com ilustração e planejamento gráfico de Eleonora Affonso, por exemplo, tem na capa da frente um gordo e caricato menino entre o sol e a nuvem carregada de chuva, com estrelas na roupa e pássaro na cabeça. Sentado no chão, com um gato deitado em sua perna e, no pescoço, uma sacola pendurada, o garoto ol ha para cima, enquanto segura um sorvete em uma mão e, na outra, um anel enfiado na luva. N o chão, entre as pernas abertas do menino, estão jogados: dados, lápis e uma nota de dinheiro. Para quem conhece a obra, é clara a referência direta ao poema $\mathrm{O}$ u isto 
ou aquilo, que lhe dá o título e se encontra na página 56, acompanhado dessa mesma ilustração. $\mathrm{N}$ a capa de trás, o mesmo menino, de costas, tem em uma de suas pernas o mesmo gato, como que andando pela capa, e um caracol corde-rosa dá movimento à cena.

0 índice, ainda no padrão convencional - a listagem com os títulos dos poemas e suas páginas correspondentes -, repete a seqüência da segunda edição, porém ganha uma ilustração à sua volta: são pássaros, tartaruga, peixinho, caracol, flores, nuvens, sol, coloridos, a saírem de uma caixa aberta, que evocam os temas e os personagens "cecilianos", o imaginário infantil.

Uma primeira página, em tom rosa forte, repete o título, com partes da ilustração da capa em cada letra. E a página de rosto, de forma colorida, identifica os nomes da autora, da editora e da obra, em cujas letras pousam um caracol e uma borboleta - insistência, pela repetição em diferentes lugares do livro, do que se pressupõe fazer parte do universo da criança: cor, bichos e flores.

A edição da N ova Fronteira, em 1987, traz as ilustrações e o projeto gráfico de Fernanda Correia D ias, neta da própria C ećlia M eireles. Segundo C amargo (1998), essa edição "tende a configurar-se como um livro-jogo, incluindo sugestões de atividades como desenhar, recortar e colar, etc., o que talvez possa desviar o olhar do leitor do texto para essas atividades." (p. 82).

N este caso, a edição ganha outros adereços de sedução para um leitor infantil que tem com o objeto livro uma relação lúdica, além daquela proposta por Cecília na temática e na linguagem de seus versos. São atividades identificadas - desenhar, recortar, colar - que têm origem em outros suportes, como as revistinhas de lazer, por exemplo, e, via de regra, desenvolvem-se com outras finalidades; agora, porém, são incorporadas à obra de C. M eireles.

A proposta de deslocamento de práticas de leitura, comumente ligadas a outros suportes e a outras linguagens, e o oferecimento de ilustrações que continuam em páginas menores, que se abrem junto do mesmo poema, chamam a criança para um jogo participativo; provocam um olhar desautomatizado do leitor acostumado a encontrar uma única e estática ilustração para o poema a que se refere; dá contemporaneidade à obra para um novo leitor.

Esta edição é a única em que o poema $\mathrm{O}$ u isto ou aquilo abre a coletânea; no entanto, as capas de fundo amarelo forte não conversam com ele. A da frente traz uma grande borboleta centralizada, colorida, de asas abertas, de costas, e um caracol pequeno incrustado na palavra "ou" do título $\mathrm{Ou}$ isto ou aquilo. $\mathrm{Na}$ capa de trás caminha uma lagarta sorridente.

Ao abrir-se o livro, a ilustração reproduz uma foto de família (crianças, jovens, senhor e senhora) em pose, num jardim: do lado esquerdo, a foto em preto e branco; do lado direito, com pequenas variações, a mesma "foto", agora colori- 
da, repete-se, ao contrário. U ma referência aos temas atribuídos como pertencentes à poesia de Cecília: crianças, pais, avós, tios, bichos, flores, família?

N as últimas páginas (146-155), um "banco de palavras ou isto ou aquilo", organizado na seqüência das letras do alfabeto, sugere uma referência ao leitor infantil (escolar) ou ao leitor que se distancia do tempo de produção da linguagem utilizada pela autora? Práticas, talvez, trazidas dos livros didáticos que comumente apresentam um vocabulário de palavras que, segundo suposição dos editores, carregam sentidos desconhecidos ou dificuldade para as crianças. $\mathrm{M}$ arca que a obra vai ganhando, como projeto editorial destinado a um leitor infantil. São tentativas de aproximação planejadas no pólo da produção editorial para proporcionar o encontro da obra com um outro leitor, talvez não previsto pela autora. D elineamento de um gesto do adulto que interpreta possibilidades e formas para que 0 encontro ocorra. $M$ arcas de uma produção, voltada para a criança, que transita nas fronteiras tênues entre a literatura e 0 didatismo.

Esta edição - "não encontrada nas livrarias" (conforme indicação da editora na contracapa) - de luxo pela qualidade do papel, pela quantidade de ilustrações em folhas duplas, pelo número de páginas que aumentam o volume, destoa daquelas comumente adquiridas pelo governo e distribuídas gratuitamente para fazerem parte do acervo das bibliotecas.

As edições de 1977 e 1987, diferentemente das duas anteriores, oferecem ao leitor um projeto editorial que chama atenção pelo colorido, pela repetição de elementos, que se deslocam das ilustrações dos poemas no interior do livro para as partes mais externas. Estratégias orientadas, talvez, pela representação do gosto e do interesse infantil pelo bucólico - flores e bichos - e por objetos (neste caso, livros) bastante coloridos.

\section{A quinta e a sexta edições - um leitor guiado}

As últimas edições de $\mathrm{Ou}$ isto ou aquilo analisadas por nós são também da N ova Fronteira (1990; 2002) e incluem textos que promovem o encontro do leitor com a obra. Adereços contemporâneos que destacam para o leitor desavisado o que poderá encontrar e como apreciar uma obra editada em épocas distantes das condições de produção em que foi criada e pensada. Adereços do universo escolar a orientar a apreciação da literatura; formas de escolarização do texto literário; compreensão sobre uma educação do leitor infantil.

A de 1990, com ilustração de Beatriz Berman, retorna ao tamanho $(23 \mathrm{~cm}$ x $16 \mathrm{~cm}$ ) e grossura (72 páginas) muito próximos ao formato modesto da segunda edição (1969). Também, como aquela, faz referência, já na capa, ao convênio "M inistério da Educação-FN DE- Biblioteca da Escola, distribuição 
gratuita". A edição de 2002, ilustrada por Thais Linhares, também em um formato retangular $(21 \mathrm{~cm} \times 27 \mathrm{~cm})$, de um livro que se amplia, pode hoje ser adquirida nas livrarias em sua 11 a impressão.

No livro ilustrado por Berman, a capa da frente sugere um jardim, com flores coloridas, folhagens e gramas, grilo e caracol - um cenário que emoldura e cerca o título da obra e os nomes da autora e da ilustradora. $N$ a edição de Linhares, as capas ganham a cor azul do céu, têm estrelas, casinha, xícara, cabecinha de carneiro, anjo, gato, peixe, flor - referências sobre o que se pode encontrar nos poemas. $\mathrm{N}$ a capa da frente, uma grande lua crescente, em amarelo forte, sustenta uma menina, cabelos longos em caracóis amarrados com laços coloridos, com um pé descalço e outro com meia, com uma mão enluvada, a segurar um guarda-chuva cor-de-rosa que sustenta um burrico; uma outra mão, sem luva, segura um escorregador (?).

M ais uma vez, as capas dos livros identificam a temática dos poemas, ilustram o jogo criado pelo título $\mathrm{O} u$ isto ou aquilo e trazem um modelo de criança como que saído de um mundo da fantasia, meio nonsense, carregado de coisas. M as, pela primeira vez, uma menina, e não mais o menino da edição de 1978.

No artigo intitulado "Entre as páginas de um livro didático; C ecília M eireles", Sena (2006) destaca que os poemas de Cecília M eireles presentes nos livros didáticos são sempre os mesmos e a escolha recai nos temas reconhecidamente mais próximos à criança, como o sonho de ser bailarina, a brincadeira com bola, as travessuras: "na temática escolhida, desenha-se a imagem de um leitorcriança que gosta de assuntos que falam de seu cotidiano infantil; além de ligar, talvez, a uma 'feminização' na representação desses leitores." (p. 20).

Em ambas as edições (1990; 2002), o encontro entre leitor e obra é mediado por textos que ocupam a capa de trás, as orelhas e a introdução do livro; que apontam valores, modos de apreciação e peculiaridades da linguagem literária. Q uase como um "ensinamento", uma didática para garantir o gostar da obra; o gostar do gênero, da autora; e a formação e a tradição de uma cultura, a educação do leitor infantil.

N a capa de trás do livro de 1990, por exemplo, o texto:

um dos mais belose importantes livros de poesia para criança, nascido da extrema sensibilidade deC ecília M eireles. O spoemasfalam desonhosefantasiasque povoam o mundo infantil. A casa da avó, osjogose brinquedos, os anjos, animais eflores ganham vida nos poemas suaves emusicais deC M . [...] com ilustrações deB eatriz Berman, artista plástica argentina radicada no Brasil econsagrada internacionalmente, tendo recebido entreoutros, o Prêmio deD esenho da Fundação J oan M iró, de Barcelona. 
destaca a importância de Cecília M eireles no gênero "poesia" para crianças; indica 0 universo do imaginário infantil como tema; aponta o estilo sensível, suave e musical da autora e, ainda, a preocupação com a escolha da ilustradora.

A capa de trás da edição de 2002, não muito diferente, embora com um texto bem menor, retoma essas idéias, reforça aquilo que ao longo do tempo a crítica colou à imagem da autora e da obra: "uma poesia feita de impressões, musicalidade e cores [...] que fala dos sonhos e fantasia do mundo infantil".

$\mathrm{N}$ a Introdução da edição de 1990, Walmir Ayala constrói uma conversa sobre o "livro mágico" com um leitor de quem, segundo ele, não se sabe e nem se pode prever a idade, mas que, com certeza, será surpreendido pela beleza e pela magia que o livro carrega. Um leitor que experienciará os mundos imaginados e cheios de mistérios criados por Cecília:

Ao ler estelivro, vocêvai sentir que os poemasfalam, com um jeito muito especial, de coisas que vocêjá viu, já pensou, já sentiu, já experimentou, ou, principalmente, já imaginou. [...] Estou fal ando de poesia, estudando com aplicação a forma correta de colocar este livro em suas mãos, e de poder ajudar na descoberta de qual quer mínimo detalhe, desses que o respeito eo amor sempreconseguem revelar deforma nova. (1990, p. 7-8).

N essa direção, na busca de aspectos que possam "garantir" o gosto e o prazer da leitura, que destacam a relevância da obra, o apresentador cria uma conversa, tentativa de aproximação com seu leitor, que também pode ser lida no texto de Sandroni: "[poemas que] falam das coisas simples da vida: da bola, do vestido, da rua, da lua, do jardim, da amizade, da morte, dos nossos medos e das nossas dúvidas [...] E você? Q uer subir pelos ares ou ficar no chão? Agora é só abrir as páginas do livro e decidir! Se isto ou aquilo". (2002, p. 9).

A insistência em apontar na obra a presença de temas ao gosto do leitor infantil, a linguagem sensível, musical e lúdica inventada pela autora vem colada à idéia de uma prática de leitura gostosa, que não exige esforços para entendimentos, para fruição. M ais do que isso, enfatiza-se certa experiência singular de leitura, só possível com a literatura.

$\mathrm{N}$ a "A presentação (que você pode pular)", da edição de 2002, assinada por Luciana Sandroni, por exemplo, a imagem da leitura é dada como aquela em que as palavras grudam na gente. No processo de criação, o escritor, aquele que pega um pote de palavras e cola uma a uma no papel. Alguns usam cola fraca, e as palavras soltam-se; e o leitor, ao virar as páginas, fica cheio de palavras nas mãos, no colo, no corpo todo, como é o caso do $\mathrm{O}$ u isto ou aquilo. $\mathrm{N}$ a edição de 1990, Ayala convoca a idéia de que 
$\mathrm{N}$ averdade, o poeta brinca com aspalavras, escolhendo-ascomo se perguntasseasi mesmo, a todo o momento: Esta ou aquela? 0 poeta as escol he atéconseguir escrever um texto diferente, bonito, interessante[...] Juntar pal avras queas pessoasnormalmentenão juntam paraformar umaidéa, como "precedepelúcia", também faz parteda arte da poesia.

Livro "mágico", livro que "gruda na gente", leitura como "porta de entrada para um mundo mágico", livro que a "gente quer morar dentro", leitura "descoberta de sentidos novos", leitura em que as palavras "bailam na nossa cabeça", palavras - brinquedos do poeta, são imagens que se repetem nos textos incluídos nessas edições, que expressam concepções; valores que circulam em torno de uma educação contemporânea do leitor de literatura.

0 leitor passa a receber orientações que 0 ajudem no encontro com essa autora, vai sendo "educado" para a sensibilidade de sua linguagem. 0 Sumário da edição de 2002 (p. 5-7) ilustra um modo didático de apresentação dos poemas, bem diferente das demais edições. $N$ esse, os poemas são organizados em duas partes, aparentemente sem nenhum critério. D ispostos em dois grupos, pode-se pensar em um outro tipo de orientação da leitura, aquela que fragmenta para não cansar o leitor, que organiza dando seqüência, que permite interrupções e retomadas, que dá um movimento direcionado ao gesto de ler.

Se, inicialmente, o livro em suas primeiras edições é objeto de sedução pela leitura que se possa fazer dos versos e das ilustrações, à medida que vai sendo mais diretamente criado para o leitor escolar ou infantil de um outro tempo, começa a trazer também a "didática" para sua leitura, como lemos nas orelhas do livro (1990): "leia em voz alta, sinta que está cantando."; ou, então, lemos na Apresentação (2002): "São poemas bons de falar porque brincam com os sons das palavras e de repente viram música." (p. 9).

$\mathrm{N}$ esse sentido, as edições, ao longo do tempo, vão agregando ao livro de literatura para criança também certa apreciação crítica deslocada de estudos de caráter mais reflexivo e teórico. O rientações sobre como ler o livro (em voz alta), sobre a singularidade da linguagem literária - estranha, mal compreendida e de difícil entendimento no universo escolar. Para um leitor infantil que inicia sua educação como leitor de literatura ou que já está no tempo distante das condições de criação desta obra; ou para o leitor-professor, que provavelmente lidará com a obra na escola, tentativas para garantir uma leitura naquilo que caracteriza a linguagem poética: a busca pela palavra perfeita, o jogo de imagens, a importância de "escrever um texto sensível, diferente, bonito, interessante e que comunica uma idéia, uma mensagem" (1990, p.8); ou, então, a importância do clássico: "O u I sto ou Aquilo éum clássico não porquefoi editado há muito tempo, mas porque os poemas parecem que foram feitos, agora" (2002, p.9). 
De qualquer maneira, o que vemos nas diferentes edições de $0 \mathrm{u}$ isto ou aquilo são inserções de idéias e discursos de outros lugares, distanciando-se da intenção de promover uma leitura mais autônoma, desgovernada e livre, mesmo quando se tem um leitor previsto como imaturo (criança) ou despreparado para apreciá-lo, na distância marcada pela linguagem, pela tematização, pelo gênero.

\section{Livros reinventados, inscrição de uma obra na memória}

$\mathrm{N}$ este artigo, nossa intenção foi buscar na história editorial de $\mathrm{Ou}$ isto ou aquilo, traduzida em seis livros, um entendimento sobre o funcionamento da produção voltada para a criança, os modos como a linguagem literária transita entre o didatismo e a especificidade de sua linguagem no encontro entre leitor e livro, os modos contemporâneos de apresentação de uma obra infantil que se torna, ao longo dos seus 40 anos de publicação, reconhecida pela crítica especializada como um clássico da literatura infantil.

Embora a primeira edição apresente um número menor de poemas em relação às demais, todas as seis aqui analisadas trazem em comum, de forma integral, o mesmo texto poético.

D esde a edição de 1964, o conjunto dos poemas permanece, ao longo do tempo, sem adaptações ou censuras em nome de uma representação do leitor infantil, que hoje pode ter se distanciado de algumas temáticas ou da linguagem postas pela autora em outras condições de produção. $\mathrm{N}$ ão há corte em relação a poemas que tematizem, por exemplo, a "rua", nem sempre mais lugar de brincar da criança urbana; nem às expressões que podem soar estranhas, como "sapé", "procissão", para a criança contemporânea. N as edições analisadas, o texto é atual e adequado porque propõe e sugere ao leitor um universo infantil caracterizado por brincadeiras, relações com a natureza, com os animais, de forma amistosa, harmônica e idealizada. Aspectos destacados sobre 0 conteúdo dos poemas nos textos de apresentação da obra não conflituam com os valores sociais, morais, éticos que são propostos quando se pensa, hoje, sobre a educação de um jovem.

As seis edições trazem outra característica em comum: a presença de ilustradores que, reconhecidos pela crítica especializada, parecem ter sido escolhidos cuidadosamente para que cada projeto editorial sele a parceria pela qualidade artística em ambas as linguagens. 0 u isto ou aquilo, em suas edições, sedimenta, no decorrer do tempo, algo que facilmente a identifica como obra pertencente ao gênero infantil: uma linguagem verbal acompanhada da imagética.

$\mathrm{M}$ as, pelos ilustradores diversos que são convocados; pelos modos como os poemas são dispostos e apresentados ao leitor; pelos textos escritos na apresen- 
tação, no prefácio, na quarta capa, por diferentes profissionais, a obra $\mathrm{Ou}$ isto ou aquilo é reinventada a cada edição, pressupondo outros significados e usos. 0 texto verbal - o conteúdo - apenas aparentemente é o mesmo, o texto aparentemente pode representar a intenção "original" da autora. Ao longo dos 40 anos, a obra vai sendo reconstruída, marcando diferenças entre uma edição e outra.

As propostas para as edições constroem e sedimentam "estratégias", propõem e tentam regular "práticas" (Certeau, 1996), agregam ao produto que oferecem à criança sentidos e valores como a educação do leitor de literatura, a importância do (re)conhecimento de uma escritora consagrada na tradição literária, a valorização da experiência da peculiaridade da linguagem construída por ela e com inventividade.

A representação do leitor inscrita em $\mathrm{O} u$ isto ou aquilo, no pólo da produção editorial, altera-se ao longo das edições analisadas. $\mathrm{N}$ as primeiras, é menos marcada a categorização do leitor como escolar, como criança, como imaturo na leitura, etc. $E$, à medida que se distanciam do momento de produção, as edições incorporam outras marcas, ligadas a um modelo de leitor infantil, naquilo que os editores pensam ser seus gostos, suas expectativas.

Também a legitimação da obra ganha novos contornos. Inicialmente lançada no interior de uma coleção - cuidadosamente criada, com autores e ilustradores reconhecidos pela crítica e com uma proposta editorial inovadora na época - , ao longo dos 40 anos, a obra ganha autonomia, posta em circulação de forma isolada. Ela passa a ser identificada como uma obra que pertence ao gênero literatura infantil e agrega na sua individualidade a chancela de um clássico que precisa ser apresentado aos seus leitores pelas marcas já instituídas pela crítica literária.

A voz do adulto cresce em direção à da criança nas páginas da apresentação, nas capas. Ela orienta modos de leitura, de apreciação de temas e de aspectos trazidos pela linguagem literária de Cecília M eireles. A intenção educadora, própria da produção cultural voltada para criança, fica mais evidente nas últimas edições (1990; 2002) do que as publicadas na década de 60.

Firmada e reconhecida como pertencente ao gênero "literatura infantil", a obra vem marcada, principalmente nos textos que rodeiam seus poemas, pela preocupação com as práticas de leitura legitimadas pelas instituições - escola, mídia, etc. - que promovem essa formação do leitor infantil contemporâneo. Esses textos ressaltam uma educação do leitor em que a ludicidade, a fantasia e o humor próprios da linguagem literária de Cecília M eireles podem ser usufruídos por uma leitura leve, prazerosa, fortuita. $\mathrm{N}$ eles, a poesia, por ser de qualidade, não exige esforço na sua recepção, no seu entendimento por parte do leitor. 
E, por último, a percepção da obra como uma mercadoria editorial exige que $\mathrm{Ou}$ isto ou aquilo se apresente visualmente como nova, diferente das demais. Assim, as seis edições analisadas mudam, ao longo do tempo, o seu projeto editorial, guiadas pelo entendimento que os sujeitos envolvidos no pólo da produção têm da criança, do seu tempo e da sociedade.

São livros com projetos editoriais fabricados e cuidadosamente reinventados à medida que querem continuar com a permanência da obra, em busca de novos leitores. Um livro não existe sem leitor; daí tantas estratégias para seduzi-lo e para inscrever a obra em sua memória. $M$ as igualmente é verdadeiro que nenhuma edição substitui a outra ou as outras. Como também é verdadeiro que nenhum livro, mesmo na mesma edição, substitui o encontro sempre singular, móvel, entre ele e seu leitor, daquele lugar e daquele tempo.

\section{Uma leitora existe sem o livro?}

M eu envolvimento com o desejo de conhecer todas as edições de $0 \mathrm{u}$ isto ou aquilo, obcecada pela história editorial dessa obra, pôs-me em busca das referidas edições. E o itinerário pela sua busca valeu-me a necessidade de registrá-lo e incorporá-lo neste artigo.

Tinha, já há algum tempo, a edição de 1977, que pertence aos meus filhos. As publicações de 1987 e 1990, também conhecidas por mim, foram facilmente adquiridas, por empréstimo, nas bibliotecas da U nicamp. A última, a de 2002, foi com tranqüilidade comprada na livraria de minha cidade. Faltavam as duas primeiras.

Tornei-me, pois, uma leitora sem o livro, ou melhor, sem dois livros.

Iniciei então uma consulta a colegas, professoras de Língua Portuguesa, uma visita a todos os sebos de C ampinas (SP) e a alguns (muitos) da cidade de SP. U ma busca pela Internet nos acervos de bibliotecas universitárias, das tradicionais, como a Biblioteca $\mathrm{N}$ acional do Rio de Janeiro, a Biblioteca $\mathrm{M}$ ário de Andrade em São Paulo (SP), o Centro de Ciências, Letras e Artes em Campinas. U ma ida às bibliotecas municipais e escolares mais antigas da nossa região. Um esforço solidário de bibliotecários que também se puseram na busca.

O s livros não estavam acessíveis a esta leitora. Algumas bibliotecas, literalmente fechadas por falta de funcionários (em licença saúde, ou sem recursos para contratação); por causa de greve da categoria; por estarem em reforma.

O s livros? Encaixotados, desaparecidos, ou quem sabe, "roubados". É o que parece ter acontecido com um livro da edição de 1987 que, na quarta capa, tinha um esparadrapo a ocultar a informação: "Governo Franco M ontoro Secretaria da Educação - Fundação para o Livro Escolar - Distribuição Gratuita" e estava disponível no sebo, por 12 reais. 
Os livros? Q ueimados, descartados, porque possíveis de serem substituídos por novas edições, após a Lei 5.765, de 18/2/1971, que regulamentou a ortografia da Língua Portuguesa, em vigor após essa data:

A indestrutibilidade do texto, supondo que seja atingida, não significaquedevam ser destruídos ossuportes particulares, historicamentesucessivos, através dos quais os textos chegam até nós, porquea rel ação da leitura dependetambém do leitor, de suas competências epráticas, eda formana qual eleencontra 0 texto lido ou ouvido. (Chartier, 1998, p. 152).

Pelas idéias de Chartier, as implicações decorrentes da destruição dos suportes de textos significam mais do que a perda do mundo dos livros em forma de rolo ou impresso. Para ele, a perda é das próprias condições de inteligibilidade, do modo de ler de seus leitores, dos códigos de leitura, do processo de produção de sentidos próprios daquele texto naquele suporte. $\mathrm{No}$ caso de $\mathrm{O} \mathrm{u}$ isto ou aquilo, ficam os poemas, o conteúdo facilmente encontrado em novas edições, transportado para outros suportes, como livros didáticos e telas do computador. $M$ as, provavelmente, ficam perdidas as experiências de leitura realizadas pelos leitores com os livros, em edições específicas. Provavelmente ficam perdidas as relações de sentidos entre o que pode ter acontecido com os leitores e os livros dados a eles para ler, um dia.

0 que foi possível localizar nessa busca? A primeira edição, na Biblioteca FCH L da USP, que, porém, não pôde ser retirada como empréstimo por causa da greve dos funcionários e dos professores. A segunda edição, na Biblioteca M ário de Andrade, que só pôde ser consultada no próprio local.

Foi por um gesto de generosidade incrível de Luis de Camargo que pude finalmente ter em mãos as duas primeiras edições. Ele já tinha conseguido todas as edições, pois estivera em busca delas para realizar sua dissertação de mestrado (1998). Alguns e-mails, um encontro que não ocorreu, um telefonema e, finalmente, pude buscar em sua casa, como empréstimo "para o tempo que eu quisesse", dois exemplares: um de 1964, outro de 1969. E, tal qual a personagem de "Felicidade Clandestina" (Lispector, 1994):

Como contar o que se seguiu? Eu estava estonteada e assim recebi o livro na mão. Acho que eu não disse nada. Peguei 0 livro [...] Sei que segurava o livro grosso com as duas mãos, comprimindo-o contrao peito. Q uanto tempo levei atéchegar em casa, também pouco importa. M eu peito estava quente, meu coração pensativo. Chegando em casa, não comecei a ler. Fingiaquenão o tinha só para depoister o susto de o ter. H oras depois abri-o, li algumas linhas maravilhosas, fechei-o denovo, fui passear pela casa, adiei ainda mais indo comer pão com 
manteiga, fingi que não sabia ondeguardara o livro, achava-o, abria-o, por algunsinstantes. Criava asmaisfalsas dificuldades, para aquela coisa clandestina queera a felicidade. A felicidade sempreiria ser clandestina para mim. (p.38-39).

Referências bibliográficas

AN D RADE, C. D. Imagens deflautinha. O u isto ou aquilo. Correio da M anhã, Rio deJ aneiro, 10 jul. 1964.

CAM ARG O , LuisH . Poesia infantil eilustração: estudo sobre 0 u isto ou aquilo. C ampinas-SP: DM ; IEL/UNICAM P, 1998.

CERTEAU, M . A invenção do cotidiano. Rio de Janeiro: Vozes, 1996.

CHARTIER, R. A ordem doslivros. Brasília: EditoraU N B, 1994.

CH ART IER, R. (O rg.). Práticasdeleitura. São Paulo: Estação Liberdade, 1996a.

CH ART IER, R. H istória cultural - entre práticas erepresentações. Rio deJaneiro: Bertrand, 1996b.

CH ARTIER, R.; CAVALLO , G. H istória da leitura no mundo ocidental. São Paulo: Ática, 1998.

DARN TO N , R. 0 beijo deL amourette M ídia, cultura erevolução. São Paulo: Companhiadas Letras, 1990.

LAJO LO , M .; ZILBERM AN , R. Literatura infantil brasileira. H istóriasehistórias. São Paulo: Ática, 1988.

LAJO LO , M .; ZILBERM AN , R. U m Brasil para crianças, para conhecer a literatura brasileira: histórias, autoresetextos. São Paulo: Global, 1993.

LISPECT O R, C. Felicidadeclandestina. In: LISPECT O R, C. 0 primero beijo eoutroscontos São Paulo: Ática, 1994. p. 38-39.

M EIRELES, C. Entrevista. A M anhã, Rio dejaneiro, v. 5, p. 339-341, 15 jan.1942.

M EIRELES, C. Problemasda literatura infantil. Belo H orizonte: I mprensa O ficial, 1951.

M EIRELES, C. O u isto ou aquilo. Ilustrações de M ariaBonomi. São Paulo: G iroflé, 1964.

MEIRELES, C. Ou isto ou aquilo. Ilustrações de Eleonora Affonso. 2. ed. São Paulo: M elhoramentos, 1969.

M EIRELES, C. O u isto ou aquilo. Ilustrações de Eleonora Affonso. 3. ed. Rio de Janeiro: Civilização Brasileira, 1977.

M EIRELES, C. O u isto ou aquilo. Ilustrações de Fernanda Correia D ias. 4. ed. Rio deJ aneiro: N ova Fronteira, 1987. 
M EIRELES, C. O u isto ou aquilo. Ilustrações deBeatriz Berman. 5. ed. Rio deJ aneiro: Editora N ova Fronteira; FN D E/M EC, 1990. (Biblioteca da escola).

M EIRELES, C. O u isto ou aquilo. Ilustrações deT hais Linhares. 6. ed. Rio deJ aneiro: N ova Fronteira, 2002.

PERROTTI, E. 0 texto sedutor na literatura infantil. São Paulo: Ícone, 1986.

PERROTTI, E. Confinamento cultural, infância eleitura. São Paulo: Summus, 1990.

SEN A, Y. M . Entre as páginas de um livro didático: C ećlila M eireles. In: FERREIRA, N . S. A. Livros, catálogos, revistasesites para o uni verso escolar. C ampinas, SP: M ercado de Letras; ALB; FAPESP, 2006. p.15-37.

ZILBERM AN , R. A literatura infantil na escola. São Paulo: G lobal, 1982.

Recebido em 20 demaio de 2008 eaprovado em 17 deabril de2009. 